\title{
ON THE ORIGIN OF MISOPHRIOID COPEPODS FROM ANCHIALINE CAVES
}

\author{
BY \\ GEOFF A. BOXSHALL ${ }^{1}$ ) and DAMIÀ JAUME ${ }^{2}$ ) \\ 1) The Natural History Museum, Cromwell Road, London SW7 5BD, U.K. \\ ${ }^{2}$ ) Instituto Mediterráneo de Estudios Avanzados (CSIC-UIB), Ctra. Valldemossa, $\mathrm{km} \mathrm{7'5,}$ \\ E-07071 Palma de Mallorca, Spain
}

\begin{abstract}
Phylogenetic relationships between the known genera of the order Misophrioida permit the identification of two lineages: one consisting of the family Misophriidae Brady, 1878 which comprises seven genera, and a new, monotypic family, the Palpophriidae Boxshall \& Jaume, 1999; the other consisting of another new family, the Speleophriidae Boxshall \& Jaume, 1999, comprising eight genera. Habitat exploitation by these families is discussed: members of the Misophriidae are primarily hyperbenthic, those of the Palpophriidae and Speleophriidae are primarily cavernicolous in anchialine habitats. The occurrence of misophriids in littoral and submarine caves is interpreted as evidence of a relatively recent landward extension of the habitat range in this family, from a shallow-water hyperbenthic ancestor. The distribution of speleophriids in anchialine caves is interpreted as resulting from a colonization episode prior to the closure of the Tethys Sea. The analysis also indicates that deep-water forms may represent a secondary colonization rather than an indication of deep-water ancestry for the entire order.
\end{abstract}

\section{RESUMEN}

El estudio de las relaciones filogenéticas entre los distintos géneros pertenecientes al orden Misophrioida ha permitido la identificación de dos linajes principales: uno compuesto por la familia Misophriidae Brady, 1878, integrada por siete géneros, y una familia nueva, Palpophriidae Boxshall \& Jaume, 1999; el otro, integrado por otra nueva familia, Speleophriidae Boxshall \& Jaume, 1999, compuesta por ocho géneros. Se discute la explotación que del hábitat hacen estas familias: los Misophriidae son primariamente hiperbénticos, mientras que Palpophriidae y Speleophriidae son cavernícolas en medio anquialino. La presencia de misofríidos en cuevas litorales y submarinas es interpretado como evidencia de una relativamente reciente extensión tierra adentro del hábitat ordinario de esta familia, a partir de un ancestro hiperbéntico propio de aguas someras. La distribución de los espeleofríidos en cuevas anquialinas es interpretada como resultado de un episodio de colonización anterior a la oclusión del mar de Tetis. El análisis indica también que las formas de aguas profundas representan una colonización secundaria mas que indicación de un ancestro de aguas profundas para el orden entero. 


\section{INTRODUCTION}

Boxshall (1989) identified two main lineages within the Misophrioida; the Misophria-lineage comprising Misophria, Benthomisophria, Misophriella, and Misophriopsis, and the Archimisophria-lineage comprising Palpophria, Dimisophria, Speleophria, Expansophria, Boxshallia, and Archimisophria. Both of these lineages had a deep-sea hyperbenthic taxon as their earliest offshoot, Misophriopsis and Archimisophria, respectively. Boxshall (1989) interpreted the results of this analysis of the taxa known at that time as evidence that the misophrioids inhabiting anchialine caves on oceanic islands belong to lineages that originated in the deep-sea. This conflicted with the view of Stock (1986) that a deep-sea origin of certain anchialine cave taxa on Atlantic islands was unlikely because of an anoxic stage in the Middle Tertiary that would have wiped out much of the bathyal-abyssal fauna.

The continuing discovery of new misophrioids from anchialine caves, and from hyperbenthic habitats in both shallow, and in deep or high latitude waters has provided a new and broader perspective on the morphological diversity of this interesting order (see Boxshall \& Jaume, 1999, and references therein). These recent discoveries have provided the new data required for a thorough re-examination of the controversial question of whether the anchialine cave misophrioids descended from ancestors found in deep water or in shallow water hyperbenthic habitats. The objective of this paper is to summarize the new evidence relevant to this question by using a phylogenetic analysis of the genera currently comprising the Misophrioida.

\section{RESULTS}

The topology presented in fig. 1, extracted from Boxshall \& Jaume (1999), was used as the basis for a proposed division of the Misophrioida into three families. The Misophriidae Brady, 1878 comprises the core Misophria-group of seven genera and is a relatively homogeneous group of mostly hyperbenthic taxa. The monotypic Palpophriidae Boxshall \& Jaume, 1999 is the sister group of the Misophriidae. The third family, the Speleophriidae Boxshall \& Jaume, 1999, comprises the other lineage identified in the analysis and contains at least seven genera (fig. 1). The position of Dimisophria is equivocal but it was tentatively placed in the Speleophriidae.

Substituting habitat types for names of genera in fig. 1 provides a simple indication of the main trends in habitat use in the Misophrioida. The family Misophriidae is a hyperbenthic group, with most of its 12 species occurring in the hyperbenthos over a wide range of depths. The genus Misophriopsis, for 


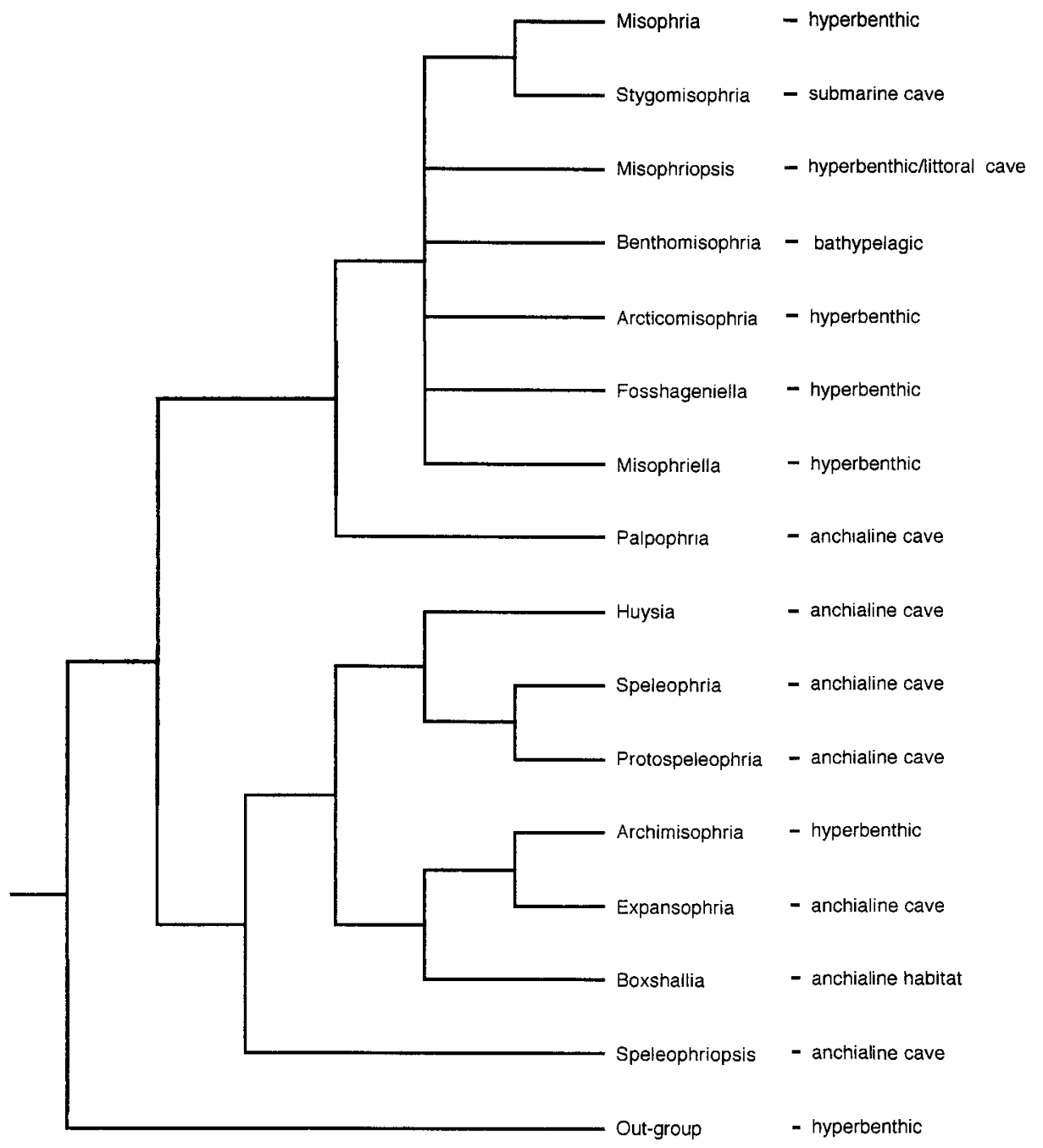

Fig. 1. Cladogram depicting inferred phylogenetic relationships between genera of Misophrioida, based on analysis using PAUP 3.11 (Boxshall \& Jaume, 1999). The major shifts in habitat utilization are also indicated.

example, contains species known from deep oceanic $(3000 \mathrm{~m})$ and shallow (8-9 m) coastal waters. A new species of Misophriopsis has now been discovered from Cova de na Mitjana on Mallorca and is currently being described by one of us (D.J.). The discovery of the new species suggests a direct route by which coastal cave habitats can be colonized from the shallow hyperbenthic. Cova de na Mitjana is not a true anchialine cave. The cave lake is extremely closely linked with the nearby coastal water as indicated by the detectable wave action within the cave. The wave action ensures mixing in the cave lake so the water column is 
not stratified (with a freshwater lens overlying deeper, poorly-oxygenated layers), as in typical anchialine caves. Cova de na Mitjana fits the definition of a littoral cave: a coastal marine cave opening below sea level, containing air plus sea water but lacking terrestrial influence. This classification is supported by the presence in the cave lake of a typically benthic marine fauna. The presence of Misophriopsis in such a cave is unremarkable since it can be viewed as a mere landward extension from its normal hyperbenthic habitat.

A similar route can be hypothesized to explain the presence of Stygomisophria kororiensis (Boxshall \& Iliffe, 1987), the sister taxon of the shallow water hyperbenthic genus Misophria (fig. 1), in South Point Cave, on the island of Koror, Palau. South Point is a submarine cave (a void completely filled with seawater) in close contact with the coastal waters, as evidenced by the detectable tidal current, the full or near full salinity, and the range of associated fauna. The occurrences of S. kororiensis and the new Misophriopsis species in coastal marine caves of the littoral and submarine types are the result of independent colonization events (fig. 1). These two types of marine caves can be viewed as ecotones, transitional zones between the open sea and true anchialine systems, which have a marked terrestrial influence particularly in the form of fresh water input. Misophriids have colonized these ecotones but have not successfully penetrated anchialine systems.

The presence of members of the Misophriidae in such coastal marine caves is an indication of one possible origin of anchialine copepod faunas: by direct range extension from the shallow water hyperbenthos. A similar, but vertical rather than landward, range extension has occurred within the family in the case of Benthomisophria. The two species of this genus are widely distributed in oceanic waters from depths of 2000 to $4000 \mathrm{~m}$ but the greatest concentrations were found in the hyperbenthic zone just above the sea bed (Boxshall \& Roe, 1980). These species are associated with the hyperbenthos but exploit a greater part of the bathypelagic water column above it.

The single species of the Palpophriidae occurs in Jameos del Agua, the classic anchialine system on Lanzarote. Its startling suite of autapomorphies suggests that it represents an ancient and distinct lineage. The sister group of the Misophriidae-Palpophriidae clade is the Speleophriidae (fig. 1), which comprises primarily specialized anchialine taxa. These relationships could be interpreted as evidence that the presence of Palpophria in the anchialine Jameos del Agua represents the retention of an ancestral habitat association and that the divergence of the Misophriidae was linked to its colonization and to exploitation of the hyperbenthic. We do not favour that interpretation. 
The members of the family Speleophriidae are almost exclusively known from anchialine habitats. The only exception is Archimisophria, the two species of which inhabit the hyperbenthic community in the deep Atlantic Ocean. The nearest relatives of Archimisophria therefore occur in anchialine habitats, as also indicated by the earlier analysis (Boxshall, 1989), however, the topology of the new cladogram (fig. 1) suggests that the deep-water genus Archimisophria descended from ancestors inhabiting anchialine systems in shallow water, rather than vice versa. This would appear to support the contention (Stock, 1986) that a deep-water origin for such anchialine cave taxa is unlikely.

Huys \& Boxshall (1991) in their review of copepod evolutionary history commented that each of the ten recognized orders of copepods had its origins in the marine benthic/hyperbenthic zone. At some point the ancestral stock of the Speleophriidae must have colonized the anchialine regime and undergone evolutionary diversification while remaining primarily associated with this extremely specialized habitat type. This ancestral colonization is the key event in the history of the Speleophriidae and we view it as both more ancient and qualitatively different from the repeated colonization of littoral and submarine caves exhibited by the Misophriidae, because it requires a greater degree of adaptation to the more extreme hydrographic conditions of anchialine systems.

\section{DISCUSSION}

A diverse suite of marine taxa including the remipedes, speleophriid misophrioid copepods, epacteriscid calanoid copepods, thermosbaenaceans, pardaliscid amphipods, and thaumatocyprid ostracods among the Crustacea, exhibits similarly extreme, disjunct distribution patterns - with foci at locations including the Canaries, Bermuda, the Galapagos, the Bahamas, Belize, the Balearics, the Yucatán, the Turks \& Caicos Islands, and northwestern Australia. The presence of some members of this faunal suite has been used as an indication that other members should also be present. Wagner (1994), for example, in discussing the distribution of the Thermosbaenacea, predicted that remipedes and the ostracod Danielopolina Kornicker \& Sohn, 1976 would be found in northwestern Australia after the discovery there of Halosbaena Stock, 1976. The search for grand unitary explanations of such distribution patterns is, therefore, not surprising.

A deep-sea origin for anchialine cave faunas has been postulated for certain taxa within the Crustacea (cf. Fuchs, 1912; Hart et al., 1985; Kornicker \& Iliffe, 1985; Boxshall, 1989). The presence of Munidopsis polymorpha Koelbel, 1892, a representative of the mainly deep-sea family Galatheidae, in Jameos del Agua on Lanzarote and in an anchialine cave on E1 Hierro (P. Oromí, pers. comm.) 
has been interpreted as evidence of a deep-sea colonization route. A deep-sea link could also be suggested for the Mictacea, which comprises one species in an anchialine cave of Bermuda, and deep-sea species from the western Atlantic and Australia. Deep-sea origins have been postulated to explain the occurrence of the pardaliscid amphipod Spelaeonicippe in anchialine caves on both sides of the Atlantic (but see Stock \& Vermeulen, 1982). The deep-sea species Danielopolina carolynae Kornicker \& Sohn, 1976 was interpreted as plesiomorphic relative to the anchialine species (Boxshall, 1989) but the recent discovery of a more plesiomorphic form from an anchialine habitat in northwestern Australia allowed Baltanás \& Danielopol (1995) to challenge this interpretation. Even from the Misophrioida there is now little support for a deep-sea origin. So, although the hypothetical deep-sea origin might be appropriate for the galatheid Munidopsis polymorpha, it appears to have very limited application to other anchialine crustaceans.

The strongest alternative to a deep-sea origin is that suggested by the clear Tethyan distribution patterns exhibited by anchialine taxa that never penetrate into the fresher parts of the cave systems. These taxa include the speleophriid misophrioids, the thermosbaenacean Halosbaena (known from the Caribbean, the Canary Islands, and northwestern Australia), and the remipede genera Lasionectes Yager \& Schram, 1986 (the Turks \& Caicos Islands and northwestern Australia), and Speleonectes Yager, 1981 (both sides of the Atlantic). Similarly, species of the ostracod Danielopolina are known from the Galápagos Islands, the Caribbean, the Canary Islands, (the South Atlantic - in deep water) and northwestern Australia. These distribution patterns support the concept of a Tethyan fauna, interpreted as relicts of the once widespread, warm-water fauna of the Tethys Sea. This fauna is regarded as having penetrated anchialine habitats from shallow-water benthic/hyperbenthic origins and may have shown the pre-adaptations referred to by Danielopol, Baltanás \& Bonaduce (1996) as "the darkness syndrome".

The Tethyan hypothesis has gained recognition as having the best explanatory power in the study of anchialine faunal distribution patterns. The invasion route into anchialine systems taken in Tethyan times by the ancestors of the Speleophriidae is likely to have been via littoral and submarine caves, directly by range extension from the shallow-water hyperbenthos. The presence of misophriids in modern littoral caves indicates that they can still exploit the ecotones along the same invasion route. The timing of colonization events is thus an important factor since it is probable that some elements of the modern anchialine fauna may have originated in relatively recent, post-Tethyan invasions. The modern anchialine fauna may be a composite of taxa with varying origins and built up over 
several episodes of colonization, but it appears to exhibit a dominant Tethyan facies.

\section{REFERENCES}

BaltanÁs, A. \& D. L. DANiElopol, 1995. Cladistic analysis of Danielopolina species (Ostracoda, Halocyprida, Thaumatocyprididae) and the origin of the anchialine fauna. Mitt. Hamburger zool. Mus.-Inst., (Suppl.) 92: 315-324.

Boxshall, G. A., 1989. Colonization of inland marine caves by misophrioid copepods, Journ. Zool., London, 219: 521-526.

Boxshall, G. A. \& D. Jaume, 1999. Discoveries of cave misophrioids (Crustacea: Copepoda) shed new light on the origin of anchialine faunas. Zool. Anz., 238. (In press.)

Boxshall, G. A. \& H. S. J. RoE, 1980. The life history and ecology of the aberrant bathypelagic genus Benthomisophria Sars, 1909 (Copepoda: Misophrioida). Bull. British Mus. (nat. Hist.), London, (Zool.) 38: 9-41.

Danielopol, D. L., A. Baltanás \& G. Bonaduce, 1996. The darkness syndrome in subsurfaceshallow and deep-sea dwelling Ostracoda (Crustacea). In: F. Uiblein, J. OTT \& M. STACHOWITSCH (eds.), Deep-sea and extreme shallow-water habitats: affinities and adaptations. Biosystematics and Ecology Series, 11: 123-143.

Fuchs, T., 1912. Über Tiefseethiere in Höhlen. Ann. K.-K. naturhist. Hofmuseums, 9: 54-55.

HaRT, C. W., JR., R. B. MANning \& T. M. IlifFe, 1985. The fauna of Atlantic marine caves: evidence of dispersal by sea floor spreading while maintaining ties to deep waters. Proc. biol. Soc. Washington, 98: 288-292.

Huys, R. \& G. A. Boxshall, 1991. Copepod evolution: 1-468. (The Ray Society, London).

KoRniCKeR, L. S. \& T. M. ILIFFE, 1985. Deeveyinae, a new subfamily of Ostracoda (Halocyprididae) from a marine cave on the Turks and Caicos Islands. Proc. biol. Soc. Washington, 98: 476-493.

Stock, J. H., 1986. A deep sea origin for cave faunas: an unlikely supposition. Stygologia, 2: 105-111.

StOCK, J. H. \& J. J. VermeUlen, 1982. Amsterdam expeditions to the West Indian islands, report 16. A representative of the mainly abyssal family Pardaliscidae (Crustacea, Amphipoda) in cave waters of the Caicos Islands. Bijdr. Dierk., 52: 3-12.

Wagner, H. P., 1994. A monographic review of the Thermosbaenacea (Crustacea: Peracarida). Zool. Verh., Leiden, 291: 1-338.

First received 21 November 1998.

Final version accepted 29 November 1998. 